\title{
T-type channels-secretion coupling: evidence for a fast low-threshold exocytosis
}

\author{
E. Carbone • A. Marcantoni • A. Giancippoli • \\ D. Guido $\cdot$ V. Carabelli
}

Received: 24 April 2006 / Accepted: 29 May 2006 / Published online: 7 June 2006

(C) Springer-Verlag 2006

\begin{abstract}
T-type channels are transient low-voltage-activated (LVA) $\mathrm{Ca}^{2+}$ channels that control $\mathrm{Ca}^{2+}$ entry in excitable cells during small depolarizations around resting potential. Studies in the past 20 years focused on the biophysical, physiological, and molecular characterization of T-type channels in most tissues. This led to a welldefined picture of the functional role of LVA channels in controlling low-threshold spikes, oscillatory cell activity, muscle contraction, hormone release, cell growth and differentiation. So far, little attention has been devoted to the role of T-type channels in transmitter release, which mainly involves channel types belonging to the highvoltage-activated (HVA) $\mathrm{Ca}^{2+}$ channel family. However, evidence is accumulating in favor of a unique participation of T-type channels in fast transmitter release. Clear data are now reported in reciprocal synapses of the retina and olfactory bulb, synaptic contacts between primary afferent and second order nociceptive neurons, rhythmic inhibitory interneurons of invertebrates and clonal cell lines transfected with recombinant $\alpha_{1}$ channel subunits. T-type channels also regulate the large dense-core vesicle release of neuroendocrine cells where $\mathrm{Ca}^{2+}$ dependence, rate of vesicle release, and size of readily releasable pool appear comparable to those associated to HVA channels. This suggests that when sufficiently expressed and properly located near the release zones, T-type channels can trigger fast low-threshold secretion. In this study, we will review the main findings that assign a specific task to T-type channels in fast exocytosis, discussing their possible
\end{abstract}

E. Carbone $(\bowtie) \cdot$ A. Marcantoni $\cdot$ A. Giancippoli $\cdot$ D. Guido

V. Carabelli

Department of Neuroscience, NIS Center of Excellence,

CNISM Research Unit,

Torino 10125, Italy

e-mail: emilio.carbone@unito.it involvement in the control of the $\mathrm{Ca}^{2+}$-dependent processes regulating exocytosis like vesicle depletion and vesicle recycling.

Keywords LVA Ca ${ }^{2+}$ channels - Capacitance increases . Neurotransmitter release $\cdot$ Synaptic activity $\cdot$ Vesicle release

\section{Introduction}

The 25th anniversary of the paper by Hamill et al. [28] is an appropriate occasion to remind that among the many important goals achieved by the "patch-clamp technique", there is also the detailed description of the biophysical features of LVA T-type channels. It was indeed few years after the publication of the famous Pfluegers Archiv's article [28] that several groups could identify and describe the unique properties of LVA channels $[2,4,6,11,12,22$, 48, 50].

LVA channels belong to the family of voltage-gated $\mathrm{Ca}^{2+}$ channels, which also includes the HVA channel types (L, N, $\mathrm{P} / \mathrm{Q}$, and $\mathrm{R}$ ). These latter activate at relatively higher voltages with respect to T-type channels and possess distinct structural and functional properties (see [14]). T-type channels are ubiquitously expressed and sustain key physiological functions like low-threshold spikes (LTS) generation, neuronal and cardiac pacemaking activities, muscle contraction, hormone release, cell growth and differentiation [33, 66, 72, 73]. Most of these functions derive from the unique properties that LVA channels are shown to possess: (1) they activate and desensitize (inactivate) at unusually negative voltages $(>-70 \mathrm{mV}),(2)$ exhibit transient kinetics due to fast and complete inactivation on sustained depolarization and deactivate slowly on repolarization, (3) are equally permeable to $\mathrm{Ca}^{2+}$ and $\mathrm{Ba}^{2+}$ 
and have small single channel conductance, (4) outlast membrane-patch excision and are preferentially blocked by low doses of $\mathrm{Ni}^{2+}$ and mibefradil.

Following this preliminary biophysical and pharmacological characterization, T-type channels have been widely investigated in nearly all tissues to uncover their functional role and molecular identity [52]. The progress of these studies, however, has been often biased by the lack of highaffinity blockers which limited the analyses to narrow ranges of voltages and, in some cases, may have caused serious underestimates of their role in specific physiological functions (see below). A sharp improvement to this approach was provided by the molecular cloning of three different pore-forming $\alpha_{1}$ subunits $\left(\alpha_{1 \mathrm{G}}, \alpha_{1 \mathrm{H}}\right.$, and $\alpha_{1 \mathrm{I}}$ also named as $\mathrm{Ca}_{\mathrm{v}} 3.1, \mathrm{Ca}_{\mathrm{v}} 3.2$, and $\mathrm{Ca}_{\mathrm{v}} 3.3$, respectively) with biophysical properties similar to the endogenous T-type channels $[17,53]$. This opened a new era of investigations, particularly for the structure-function studies, which have brought important new insights into the mechanisms of ion selectivity and activation-inactivation coupling [52] (see also [10]).

At present, T-type channels are recognized to play a critical role in many physiological functions in which a low-threshold $\mathrm{Ca}^{2+}$ entry is required to trigger or sustain specific cell activities. This is particularly true for the generation of LTS, oscillatory cell activity, and hormone secretion in cells lacking a vesicular apparatus. The critical role of T-type channels on important physiological functions is strengthened by the fact that either recruitment, overexpression, or malfunctioning of these channels is reported in a number of pathologies, including cardiac hypertrophy [65], hypertension [43], heart failure [16], absence epilepsy [68], neurogenic pain [1], and Parkinson's disease [73]. Most recently, T-type channels are shown to control the vesicular release of neurotransmitters in neurons and neuroendocrine cells [42, 51], and very recent data indicate that LVA channels are involved in fast catecholamine release in adrenal chromaffin cells [9, 25].

In this review, we will focus on the role that T-type channels play in the control of fast vesicular exocytosis. This aspect has been largely overlooked in the past and, given its importance, may turn of broad interest for future investigations. As the contribution of T-type channels to exocytosis derives mainly from channels located at distal dendrites and spines, the progress in this field will rely on whether optical techniques for recording $\mathrm{Ca}^{2+}$ signaling and electrophysiological detection of vesicle secretion will improve their sensitivity to reveal $\mathrm{Ca}^{2+}$ signals and exocytic events in narrow regions of neuronal terminals. T-type channels are known to play also a main role in the control of hormone release from cells lacking secretory vesicles and exocytotic mechanisms. This aspect, however, will not be treated in this study because there are already excellent articles and up-to-date reviews covering this issue $[40,55$, $58,61]$.

\section{Transmitter release and T-type channels in neuronal terminals}

\section{A brief overview}

Pharmacological studies and immunocytochemical characterization of $\mathrm{Ca}^{2+}$ channel distribution suggest that $\mathrm{N}$ - and $\mathrm{P} / \mathrm{Q}$-type channels are the predominant species controlling synaptic transmission in central neurons [54]. The two $\mathrm{Ca}_{\mathrm{v}} 2$ channel types bind to syntaxin and synaptotagmin through a "synprint" region [45] and are closely associated to the SNARE complex. They mediate vesicle docking, fusion, and neurotransmitter release in highly specialized presynaptic regions (active zones). Colocalization of $\mathrm{N}$ - and P/Q-type channels to the active zones ensures high $\mathrm{Ca}^{2+}$ concentrations and fast synchronous synaptic responses during action potential-evoked neurotransmitter release. In this way, probability of release $(p)$ associated to N- and P/ Q-type channels is relatively large when $\left[\mathrm{Ca}^{2+}\right]_{\mathrm{i}}$ is elevated above $10 \mu \mathrm{M}$, ensuring high rates of vesicle release during rapid responses ( 300 vesicles/ms; [57]). There are, however, exceptions to this general rule suggesting that also other voltage-gated $\mathrm{Ca}^{2+}$ channels (R-, L-, and T-type) play a role in the control of presynaptic $\mathrm{Ca}^{2+}$ levels in a variety of neurons.

In cerebellar parallel fibers [44] and hippocampal CA3CA1 synapses [70], a conspicuous fraction of $\left[\mathrm{Ca}^{2+}\right]_{\mathrm{i}}$ persists in the presence of $\omega$-CgTx, $\omega$-Aga-IVA, and nifedipine, suggesting that either R- or T-type channels may contribute as well to $\mathrm{Ca}^{2+}$ elevations in these terminals during synaptic transmission. Evidence for a contribution of R-type channels on glutamate release is reported at the calyx of Held [71], and R-type channels are shown to replace $\mathrm{P} / \mathrm{Q}$-type channels at the mouse neuromuscular junction in KO mice lacking P/Q-type channels [67]. Ltype channels are shown to control glutamate release in rod photoreceptor terminals [69] and to colocalize at the hot spots of bipolar cell terminals [5]. L-type channels are expressed also in AII amacrine cells and localized at the distal dendrites where synaptic transmission takes place [27]. The most noteworthy is that L-type channels regulate transmitter release in single boutons of cultured rat hippocampal neurons [46] and are involved in presynaptic $\mathrm{Ca}^{2+}$ accumulation during high-frequency activity in GABAergic hippocampal neurons [36]. This helps maintain high rates of vesicle release during tetanic stimulation and to enhance the probability of transmitter release during posttetanic periods. In cerebral cortex, L-type channels control short-term plasticity of GABA release during 
presynaptic firing rates in the gamma frequency range $(40 \mathrm{~Hz})$ [37]. The action is likely mediated by second messengers, which may activate various kinases like myosin light-chain kinases, controlling vesicle recycling and mobilization from a vesicle reserve pool.

To date, there is also increasing evidence that T-type channels mediate neurotransmitter release in a number of neurons. They control the response to graded depolarizations in rod bipolar neurons [51, 60], are involved in neurotransmitter release in dendrodendritic reciprocal synapses between granule cells (GCs) and mitral/tuftet cells of olfactory bulbs $[20,21]$, control spike-mediated and graded synaptic transmission between oscillatory heart interneurons of leech [34], and regulate the frequency of spontaneous excitatory postsynaptic currents (mEPSCs) in nociceptive neurons [3]. Looking closely at these reports, it appears evident that T-type channels play a role in those neurons that either use graded potentials for signal transmission or display $\mathrm{Ca}^{2+}$ signals at the synaptic terminals in dendrites and spines that are strongly dependent on the holding membrane potential. In all cases, the indication is unambiguous and brings indisputable evidence in favor of a direct role of T-type channels on neurotransmitter release.

T-type channels control GABA release in invertebrate inhibitory interneurons

In the leech, the neuronal network generating rhythmic heartbeats includes two segmental bilateral pairs of reciprocal inhibitory interneurons. The bilateral neurons are active and alternate bursts, which inhibit one another via graded and spike-mediated transmission. T-type channels mediate the graded response, whereas L-type channels control the spike-mediated transmission [41]. Simultaneous recordings of presynaptic $\mathrm{Ca}^{2+}$ currents, presynaptic changes of $\mathrm{Ca}^{2+}$ fluorescence, and postsynaptic inhibitory postsynaptic currents (IPSCs) show that transient T-type currents at $-35 \mathrm{mV}$ produce sustained $\left[\mathrm{Ca}^{2+}\right]$ increases at the fine neuritic branches near the region of synaptic contact. The $\left[\mathrm{Ca}^{2+}\right]$ increases at the neuronal endings are closely associated to transient IPSCs [34]. There is nice correlation between presynaptic $\mathrm{Ca}^{2+}$ increases and rise of postsynaptic conductance and an even better correlation between the transient time course of T-type currents and transient IPSCs, proving an unequivocal link between LVA channels activation and graded postsynaptic response in these inhibitory interneurons. T-type channels in leech heart interneurons also control the background $\left[\mathrm{Ca}^{2+}\right]$ changes that modulate the strength of spike-mediated synaptic transmission [35]. In this view, T-type channels appear critical to the control of neurotransmitter release, which set the oscillatory rhythms of leech heartbeats.
T-type channels regulate GABA release in olfactory bulbs

T-type channels have a unique functional role also at the large spines of GCs that form dendrodendritic reciprocal synapses with mitral and tufted cells of olfactory bulbs. As shown by several groups, the distal spines of GCs possess presynaptic (transmitter-releasing) and postsynaptic (transmitter-receiving) elements. These terminals express sufficient densities of T-type channels to modulate transmitter release [20]. The presence of T-type channels is evident by two-photon $\mathrm{Ca}^{2+}$ imaging measurements showing that $\mathrm{Ca}^{2+}$ transients at the spines and adjacent dendrites of GCs are strongly dependent on membrane potential: decreasing their size with depolarization and increasing with hyperpolarization. Both the voltage dependence and time course of inactivation of $\mathrm{Ca}^{2+}$ transients are consistent with the known properties of T-type channels, and $\mathrm{Ca}^{2+}$ signals appear markedly reduced by applications of $\mathrm{Ni}^{2+}(100 \mu \mathrm{M})$ and mibefradil $(1-10 \mu \mathrm{M})$. Mibefradil reduces also the action potential-evoked synaptic transmission from granule to mitral cells. In this case, action potentials are evoked by extracellular stimulation, while inhibitory postsynaptic potentials (IPSPs) are recorded in whole-cell mode at the soma of mitral cells. Under these conditions, small IPSPs with short latency and slow decay time constant can be recorded in a number of mitral cells. The IPSPs are fully blocked by bicuculline and strongly attenuated by $10 \mu \mathrm{M}$ mibefradil, suggesting that they are mediated by $\mathrm{GABA}_{\mathrm{A}}$ receptors and that mibefradil-sensitive $\mathrm{Ca}^{2+}$ channels contribute to at least half of the global inhibition of mitral cells induced by GC stimulation. These findings uncover a dual role for T-type channels on both the control of GABA release from dendritic spines and the graded regulation of GC-mediated lateral inhibition in the olfactory bulb. A graded "low-threshold" control of GABAergic synaptic release mediated by T-type channels may represent a new way to gate the entry of olfactory information to the cortex [21].

T-type channels regulate the frequency of mEPSCs in nociceptive neurons

Increasing evidence indicates that T-type channels play a key role in the control of nociceptive signaling [1]. LVA channels are highly expressed in mammalian sensory neurons [13, 22, 59], and upregulation of their current by reducing agents like DTT or endogenous L-cysteine induces thermal hyperalgesia in animal models of neuropathic pain [64]. T-type channels are also directly involved in the control of synaptic activity between primary afferents and second-order nociceptive neurons of the dorsal horn of the spinal cord by controlling the frequency of spontaneous EPSCs (mEPSCs) mediated by AMPA/kainate receptors 
[3]. T-type channel blockers like $\mathrm{Ni}^{2+}(100 \mu \mathrm{M})$, mibefradil $(5 \mu \mathrm{M})$, and $\mathrm{La}^{3+}(5 \mu \mathrm{M})$ are very effective in drastically reducing the frequency of mEPSCs without significantly affecting the latency and amplitude of action potentialevoked EPSCs. In contrast, HVA channel blockers like $\mathrm{Cd}^{2+}(50 \mu \mathrm{M})$ and $\omega$-CgTx-GVIA $(1 \mu \mathrm{M})$ can fully block the EPSCs without affecting the frequency of mEPSCs. Worth mentioning is the observation that small depolarizations induced by raising $[\mathrm{K}]_{\mathrm{o}}$ to $10 \mathrm{mM}$ produce a marked increase of mEPSCs frequency, fully prevented by $5 \mu \mathrm{M}$ mibefradil. This indicates that spontaneous glutamate release near resting conditions is effectively controlled by T-type channels in nociceptive neurons. Because mEPSCs occur often enough to influence postsynaptic neuronal excitability, it is evident that the availability of lowthreshold T-type channels alters the excitability level of nociceptive neurons. Excitatory transients occurring at a rate of $10-30 / \mathrm{s}$, each lasting $10-30 \mathrm{~ms}$, can easily coincide with the evoked activity of other terminals and summate to threshold levels for a postsynaptic afferent neuron, lowering the threshold of pain sensation.

T-type channels contribute to fast glutamate release in retinal bipolar cells

In mammalian retina, T-type channels are coexpressed with L-type channels in rod bipolar cells [30] and contribute to neurotransmitter release at the reciprocal synaptic contacts that bipolar cells form with A17 and AII amacrine cells [51, 60]. Several lines of evidence support a functional role and a tight coupling of T-type channels to glutamate release in this preparation. A first evidence concerns the high density of T-type channels expressed in these cells compared to Ltype channels $[51,60]$. The two channel types give rise to $\mathrm{Ca}^{2+}$ currents of comparable amplitudes $(60 \mathrm{pA}$ at $-40 \mathrm{mV}$ for the LVA and $40 \mathrm{pA}$ at $-10 \mathrm{mV}$ for the HVA, [51]), which implies rather similar densities if correcting for the different driving force, single channel conductance, and assuming equal open probability for the two channels. A second evidence concerns the strict voltage-dependent correlation existing between LVA currents and membrane capacitance changes in isolated rod bipolar cells [51] (see below). Finally, there is strong correspondence between the time course of presynaptic $\mathrm{Ca}^{2+}$ currents of bipolar cells and the fast glutamatergic responses recorded in synaptically interconnected amacrine cells [60].

At the synapses formed by bipolar and AII cells, the Ttype channels recruited by strong hyperpolarization $(-100 \mathrm{mV})$ give rise to a transient low-threshold presynaptic $\mathrm{Ca}^{2+}$ current that markedly increases the amplitude of fast EPSCs with little changes to its transient time course [60]. Indeed, the EPSCs recorded in AII cells are transient also when L-types are the only $\mathrm{Ca}^{2+}$ channels contributing to the presynaptic current, but the contribution of the T-type current almost doubles the amplitude of AMPA-mediated EPSCs. T-type currents are almost four times the L-type currents elicited from $-50 \mathrm{mV}$ holding potential and have all the hallmarks of LVA channels: low-threshold of activation, fast inactivation, and slow deactivation.

These findings suggest unequivocally that, when available, T-type channels contribute to neurotransmitter release with the same efficiency of HVA channels. The slight delay in the synaptic response $(\sim 5 \mathrm{~ms})$ introduced on step depolarizations from very negative holding potentials $(-100 \mathrm{mV})$ does not seem to be attributable to the contribution of T-type channels. In addition, the recruitment of T-type channels in retinal bipolar cells is already effective at holding potentials around $-80 \mathrm{mV}$ [51], and synaptic activity at these potentials, when T-type channels are available and L-type channels are blocked by $10 \mu \mathrm{M}$ nimodipine, appears extremely fast. This is proved by the short delay $(<10 \mathrm{~ms})$ existing between the raising of T-type current at $-40 \mathrm{mV}$ and the appearance of reciprocal GABAergic synaptic activity in identified bipolar cells of retinal slices [51]. Notice that the reciprocal inhibitory responses in bipolar cells, which appear as rapid fluctuations on top of the conventional T-type current, are always preceded by an excitatory synaptic response from bipolar to amacrine cells. Under these conditions, the true synaptic delay between T-type channel activation and glutamate release is limited to few milliseconds and is thus comparable to the synaptic delays associated to $\mathrm{N}$ - and $\mathrm{P} / \mathrm{Q}$-type channels.

\section{T-type channels-secretion coupling viewed through high-resolution capacitance changes}

Fast exocytosis and T-type currents in retinal bipolar cells

Strong evidence that T-type channels mediate rapid neurotransmitter release in retinal bipolar cells comes from the work of Pan et al. [51] in which glutamate release is directly measured by membrane capacitance increases $(\Delta C \mathrm{~s})$ associated to increases of membrane surface area during presynaptic vesicle fusion [47]. In isolated bipolar cell, activation of T-type currents results in a net $\mathrm{Ca}^{2+}$ influx in the presynaptic endings and fast exocytosis that is detected as $\Delta C$ increases. Capacitance increases induced by $\mathrm{Ca}^{2+}$ currents associated to 500-ms depolarizing pulses to $-10 \mathrm{mV}$ are in the order of $13 \mathrm{fF}$ (corresponding to the release of 169 synaptic vesicles, if $1 \mathrm{fF}$ is associated to the release of 13 vesicles with $50 \mathrm{~nm}$ mean diameter) and are fully abolished by $4 \mathrm{mM} \mathrm{Co}^{2+}$ or by replacing intracellular EGTA with BAPTA. Inhibition of exocytosis by BAPTA proves unequivocally that capacitance changes evoked on 
step depolarizations are induced by elevations of intracellular $\mathrm{Ca}^{2+}$ entering the cell through voltage-gated $\mathrm{Ca}^{2+}$ channels ( $\mathrm{T}$ - and L-types). Consistent with this is also the observation that the $\Delta C \mathrm{~s}$ increase to about $20 \mathrm{fF}$ when lower EGTA concentrations $(0.5 \mathrm{mM})$ are used in place of normal EGTA $(5 \mathrm{mM})$. Capacitance increases occur also at very low membrane voltages $(-40$ to $-30 \mathrm{mV})$ where LVA channels can be recruited by holding the axon terminals at $-85 \mathrm{mV}$. These "low-threshold" capacitance changes are in the order of $7 \mathrm{fF}$ and are fully blocked by $10 \mu \mathrm{M}$ mibefradil. Nimodipine $(10 \mu \mathrm{M})$ has no action on them but drastically reduces the $\Delta C \mathrm{~s}$ at $-10 \mathrm{mV}$, which are mainly associated to the L-type channels expressed in rod bipolar cells. The work of Pan et al. [51] thus furnishes the most direct evidence that T-type channels can indeed support fast exocytosis in synaptic terminals subjected to graded depolarizations.

How fast do T-type channels mediate the exocytotic response? Presently, there are no data available on capacitance measurements at intervals below $500 \mathrm{~ms}$, and thus it is impossible to make precise estimates of the initial rate of vesicle release and $\mathrm{Ca}^{2+}$ dependence of exocytosis in retinal bipolar cells. However, Pan et al. showed very clearly that intracellular $\mathrm{Ca}^{2+}$ fluxes at the presynaptic terminals of bipolar cells raise with time constants in the order of 100-200 ms, and thus it is possible that capacitance changes will follow this speed. In addition, as pointed out above, LVA currents lasting $50 \mathrm{~ms}$ can evoke reciprocal inhibitory currents in bipolar cells of retinal slices. A transient fluctuating current associated to the activity of $\mathrm{GABA}_{\mathrm{A}}$ receptors is already evident after $10 \mathrm{~ms}$ from the start of the current [51], indicating that LVA channels are capable of stimulating neurotransmitter release within very short times. Thus, it is likely that T-type channels may trigger neurotransmitter release in bipolar cell and contribute to the overall retinal information processing.

Capacitance changes in pheochromocytoma cell lines expressing recombinant $\alpha_{1 \mathrm{G}} \mathrm{Ca}^{2+}$ channels

T-type channels are effectively coupled to secretion also when they are overexpressed in a mouse pheochromocytoma cell line (MPC9/3L) that lacks endogenous $\mathrm{Ca}^{2+}$ channels but contains secretory vesicles and the protein components necessary for exocytosis [29]. MPC9/3L cells secrete dopamine and catecholamines when $\mathrm{Ca}^{2+}$ enters the cell through exogenously applied $\mathrm{Ca}^{2+}$ ionophores or when heterologous $\mathrm{Ca}^{2+}$ channels open on step depolarizations. The interesting aspect of this secretory cell line is that newly expressed $\alpha_{1 \mathrm{G}}$ T-type channels give rise to $\mathrm{Ca}^{2+}$ current densities $(70 \mathrm{pA} / \mathrm{pF})$ that are significantly smaller than those associated with $\alpha_{1 \mathrm{~B}} \mathrm{~N}$-type channels (400 pA/ $\mathrm{pF})$ but produce capacitance increases with comparable efficiency. In fact, dividing the capacitance changes for the quantity of $\mathrm{Ca}^{2+}$ charges gives mean efficiencies of $0.5 \mathrm{fF} /$ $\mathrm{pC}$ for the N-type channel vs $0.6 \mathrm{fF} / \mathrm{pC}$ for the T-type channel and similar values for the $\alpha_{1 \mathrm{C}}$ L-type channel that is expressed at even lower densities. T-type channels are also capable of inducing cumulative capacitance increases during brief trains of 5-10 depolarizations of $10 \mathrm{~Hz}$, suggesting that they can sustain marked exocytosis also when activated at frequencies comparable to sympathetic stimulation $(2-20 \mathrm{~Hz})$.

The rationale for these observations is that in MPC $9 / 3 \mathrm{~L}$ cells, all $\mathrm{Ca}^{2+}$ channels can functionally couple to release sites and control rapid exocytosis. Thus, the presence of protein components such as syntaxin and SNAP-25, which are essential components of the SNARE complex mediating vesicle fusion, and the expression of high densities of $\mathrm{N}$ type channels do not produce preferential couplings between $\mathrm{Ca}^{2+}$ entry and vesicle release. Also, the fact that N-type channels possess a "synprint region", which is absent in T- and L-type channels and is necessary for binding of syntaxin, appears not to be a critical element for mediating fast vesicle depletion in MPC9/3L cells.

T-type channels and fast capacitance changes in rat melanotropes

Indications that T-type channels are effectively coupled to large dense-core vesicles (LDCVs) secretion come also from $\Delta C$ measurements in rat melanotropes. These cells express all types of voltage-gated $\mathrm{Ca}^{2+}$ channels (HVA and LVA), which fully control the release of predocked LDCVs during action potential stimulation [42]. T-type channels in rat melanotropes contribute to a small fraction of the total current and produce a mean $\Delta C$ increase of about $7 \mathrm{fF}$ during $40 \mathrm{~ms}$ step depolarization that is only about half the $\Delta C$ associated to HVA channels (L-, N-, P/Q-, and R-type). Normalizing the capacitance changes for the quantity of $\mathrm{Ca}^{2+}$ ions entering the cells through open channels $\left(\mathrm{Ca}^{2+}\right.$ current integral), it can be shown that T-type channels control secretion with the same efficacy of HVA channel types. The immediate significance of this result is that $\mathrm{T}$ type channels are coupled to LDCVs with the same strength of all the HVA channels. It is interesting to notice, however, that in rat melanotropes as in chromaffin cells, voltagegated $\mathrm{Ca}^{2+}$ channels are not colocalized with LDCVs. This implies some delay between $\mathrm{Ca}^{2+}$ entry and vesicle secretion, which may result in poor coupling between single action potentials and exocytosis if the action potential lasts a few milliseconds and $\mathrm{Ca}^{2+}$ must diffuse considerable distances $(200-300 \mathrm{~nm})$ to reach docked vesicles [38]. This however is not the case of rat melanotropes in which action potentials last very long (50-300 ms) and $\mathrm{Ca}^{2+}$ entry persists for the entire duration 


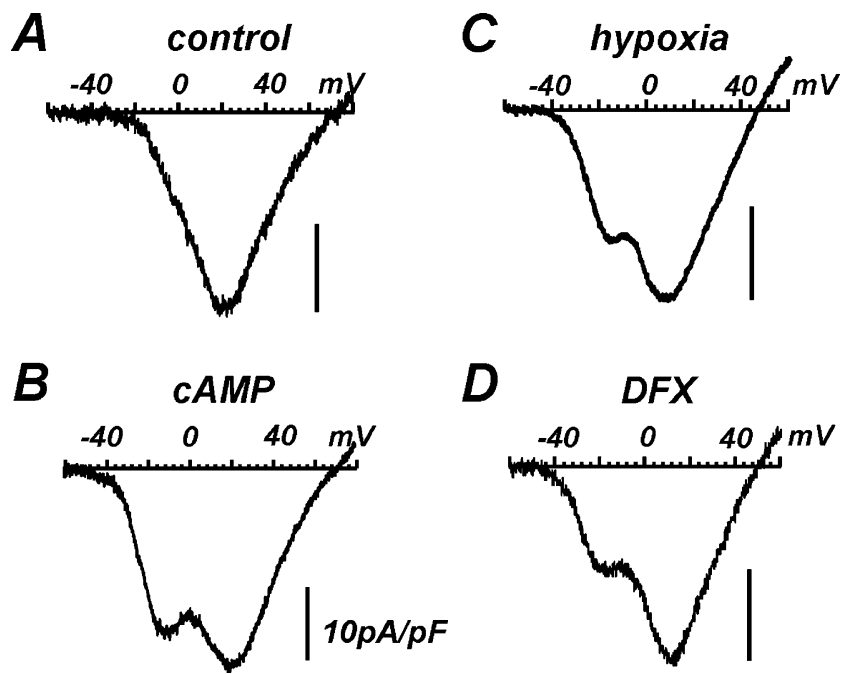

Fig. 1 Recruitment of $\alpha_{1 \mathrm{H}}$ T-type currents after exposure to cAMP, chronic hypoxia, and the hypoxia mimicking agent deferoxamine (DFX). a, b Whole-cell $\mathrm{Ca}^{2+}$ currents recorded in $10 \mathrm{mM} \mathrm{Ca}^{2+}$ during a ramp command from -60 to $+60 \mathrm{mV}$ from $-80 \mathrm{mV}$ holding potential in control RCCs and from RCCs pretreated with $200 \mu \mathrm{M}$ pCPT-cAMP and incubated for 5 days. Notice the second "lowthreshold peak" associated to the $\alpha_{1 \mathrm{H}}$ T-type currents recruited after cAMP treatment (see [49]). c, d Ca ${ }^{2+}$ currents recorded in patchperforated conditions $\left(5 \mathrm{mM} \mathrm{Ca}^{2+}\right)$ during a ramp command from -60 to $+60 \mathrm{mV}$ ( $-80 \mathrm{mV}$ holding potential) in RCCs exposed overnight to a $5 \% \mathrm{CO}_{2}$ and $3 \% \mathrm{O}_{2}$ atmosphere (hypoxia) or to $300 \mu \mathrm{M}$ deferoxamine that activates hypoxia-inducible transcription factors. Notice the appearance of a "low-threshold peak" in both cases. Expression of $\alpha_{1 \mathrm{H}}$ T-type channels during hypoxia has been reported also in PC12 cells [19]

of the depolarization. Under these conditions, all voltagegated $\mathrm{Ca}^{2+}$ channels can contribute to secretion by different degrees during the various phases of action potential generation. In the case of T-type channels, they activate around $-60 \mathrm{mV}$ and contribute to the slow initial phase of depolarization and to the "low-threshold" component of exocytosis with the same efficacy of HVA channels. This is shown by simultaneously recording capacitance changes and $\mathrm{Ca}^{2+}$ currents while clamping the cell with truncated action potentials to separate different parts of action potential stimuli. T-type channels produce small $\Delta C$ s of $2.2 \mathrm{fF}$ (equivalent to the release of two LDCVs) that normalized for the quantity of $\mathrm{Ca}^{2+}$ charges furnishing a $\mathrm{Ca}^{2+}$ dependence similar to that of HVA channels. This ensures that exocytosis takes place over the entire duration of the action potential with the same efficacy regardless of the type of open $\mathrm{Ca}^{2+}$ channel.

Capacitance changes associated to T-type channels in rat chromaffin cells

As reported by various groups, T-type channels are either absent or weakly expressed in bovine and rat chromaffin cells (RCCs) $[15,23,24,31]$ but can be expressed when RCCs are exposed to cAMP for several days [25, 49], after overnight incubation in hypoxic conditions $\left(3 \% \mathrm{O}_{2}\right)$ or in the presence of the hypoxia mimicking factor deferoxamine (DFX) (Fig. 1; see also [9] and [19]). Under these conditions, newly expressed $\alpha_{1 \mathrm{H}}$ T-type channels appear to be effectively coupled to catecholamine secretion and produce rapid exocytic events that closely resemble those produced by HVA channels [25]. The functional coupling between T-type channels and the exocytotic apparatus of chromaffin cells allows precise measurements of the elementary parameters controlling secretion, which are

$B$
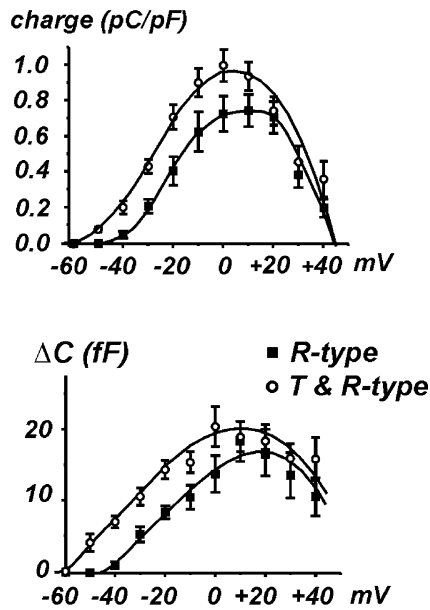

Fig. 2 "Low-threshold" capacitance changes associated with T-type channels. a Secretory responses evoked by R- and T-type currents from a control RCC and after exposure to pCPT-cAMP recorded in patch-perforated mode. RCCs were incubated with $\omega$-toxins, and nifedipine was in the bath. b Quantity of $\mathrm{Ca}^{2+}$ charge and corresponding secretion measured as $\Delta C$ increases at the potentials indicated. The quantity of charge was calculated as the time integral of the current entering during the $100 \mathrm{~ms}$ depolarization (adapted from [25]) 


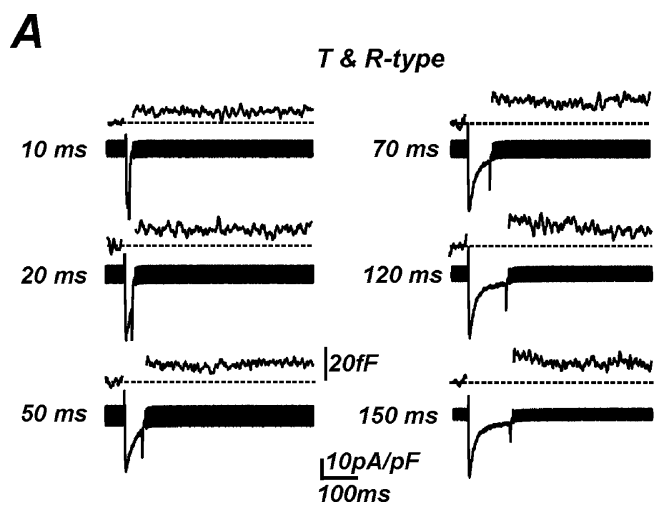

B

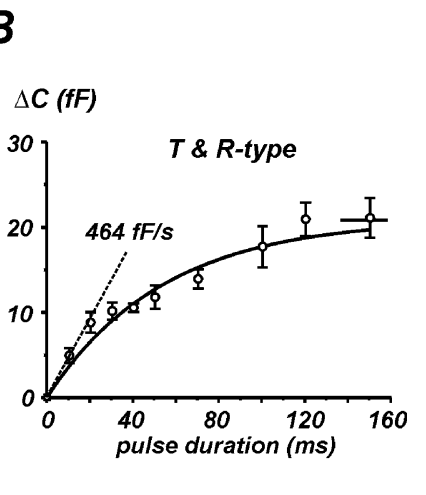

Fig. 3 T-type channels and maximal rate of vesicle depletion in RCCs. a RCCs were pretreated with $\omega$-toxins and nifedipine and depolarized with pulses of increasing length (from 10 to $150 \mathrm{~ms}$ ) at $-20 \mathrm{mV}$ to progressively deplete the pool of vesicles ready for release. b Plot of $\Delta C$ increases vs the corresponding pulse length. Data are

worth discussing in this study. In addition, chromaffin cells express all kinds of voltage-gated $\mathrm{Ca}^{2+}$ channels (L-, N-, P/ Q-, R-, and T-type) and thus represent an ideal system for comparing the role of each channel type to secretion.

$\alpha_{1 \mathrm{H}}$ T-type channels have unique properties in controlling secretion, which derive from the peculiar characteristics of their activation-inactivation gating. First, secretion starts at significantly negative membrane potentials $(-50$ and $-40 \mathrm{mV}$ ), as soon as T-type channels carry sufficient $\mathrm{Ca}^{2+}$ ions inside the cell to trigger exocytosis (Fig. 2a). Second, the relationships of capacitance changes and quantity of charge vs voltage $[\Delta C(V)$ and $Q(V)]$ do not show "double peaks" as for the $I / V$ characteristics [11-13] but rather a sharp broadening due to the constant contribution of T-type channels to both $\Delta C(V)$ and $Q(V)$ over a wide range of voltages (Fig. 2b). This derives from the weak voltage dependence of the quantity of charges passing through transiently open T-type channels. In fact, the sharp increase of the peak current with increasing voltages is followed by an increased rate of inactivation that

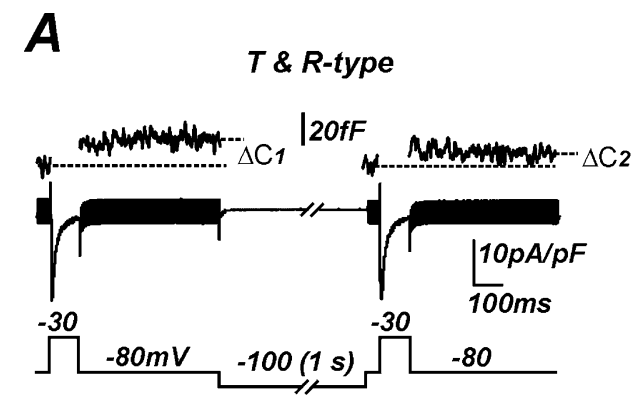

averaged from 20 cAMP-treated cells as the one of panel a. The solid curve is an exponential fit with $\tau=54 \mathrm{~ms}$ and maximal value indicated by the asymptote $(21 \mathrm{fF})$. The dashed line drawn to fit the first two points at 10 and $20 \mathrm{~ms}$ has a slope of $464 \mathrm{fF} / \mathrm{s}$ and indicates the maximum rate of vesicle depletion (adapted from [25])

limits the quantity of $\mathrm{Ca}^{2+}$ charges during pulses of $100 \mathrm{~ms}$. Third, the increased capacitance associated to T-type channels is effectively blocked by low concentrations of $\mathrm{Ni}^{2+}(50 \mu \mathrm{M})$, which also block $\alpha_{1 \mathrm{H}}$ T-type currents [39]. Fourth, long-term cAMP treatment, chronic hypoxia, or DFX recruits T-type channels without altering HVA channels' density and their related secretion [25].

Rate of vesicle release, $\mathrm{Ca}^{2+}$ dependence, and size of immediately releasable vesicles coupled to $\alpha_{1 \mathrm{H}}$ T-type channels

Even if $\alpha_{1 \mathrm{H}}$ channels have unique gating properties, they contribute to secretion with kinetics, $\mathrm{Ca}^{2+}$ dependence, and probability of release that are comparable to that of HVA channels normally expressed in RCCs. This is suggested by several observations. First, the time course of depolarization-evoked exocytosis is exponential, with an initial maximal rate of release of $464 \mathrm{fF} / \mathrm{s}$ (equivalent to $\sim 464$ vesicles/s if assuming $1 \mathrm{fF}$ as the unitary capacitance
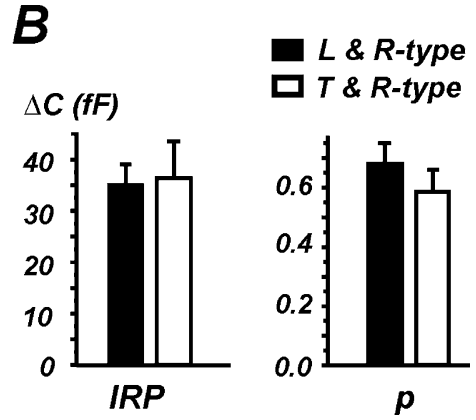

Fig. 4 T- and L-type channels mobilize the same IRP and induce comparable probability of release. a Double-pulse protocol for estimating the IRP size and the probability of release $(p)$. Two depolarizations of $100 \mathrm{~ms}$ at $-30 \mathrm{mV}$ were applied consecutively after a 1 -s interval to $-100 \mathrm{mV}$ as illustrated. Each pair of depolarization was repeated at least three times, and values of $\Delta C_{1}$ and $\Delta C_{2}$ were

averaged for each cell. b Bar histograms indicate the calculated values of $\operatorname{IRP}=\left(\Delta C_{1}+\Delta C_{2}\right) /\left(1-\left(\Delta C_{2} / \Delta C_{1}\right)^{2}\right)$ and probability of release $p=\left(1-\Delta C_{2} / \Delta C_{1}\right)$ (see [26]) associated to T- and L-type channels. The RCCs contained also R-type channels that were common to both groups of cells (adapted from [8] and [25]) 


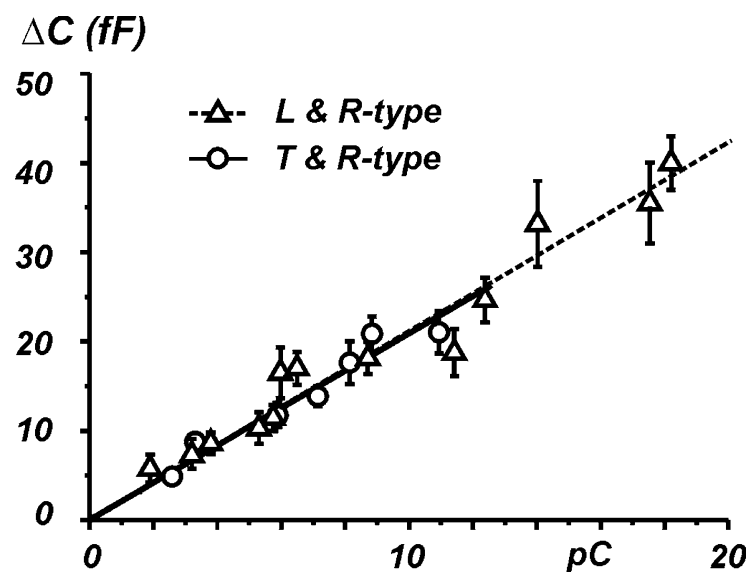

Fig. 5 T- and L-type channels are coupled to exocytosis with the same efficacy for $\mathrm{Ca}^{2+} . \Delta C$ increases vs the corresponding quantity of charge for cAMP-treated RCCs expressing T- and R-type channels and incubated in a medium containing $\omega$-toxins and nifedipine (empty circles, solid line) compared to $\Delta C$ increases induced by $\mathrm{L}$ - and $\mathrm{R}$ type channels expressed in control RCCs treated with $\omega$-toxins (empty triangles, dashed line). The linear regressions have almost equal slope: $2.0 \pm 0.1 \mathrm{fF} / \mathrm{pC}$ (T- and R-type) and $2.1 \pm 0.1 \mathrm{fF} / \mathrm{pC}$ (L- and Rtype) (adapted from [8] and [25])

of large dense-core vesicles) that decreases drastically with time (Fig. 3). $\Delta C$ saturates with prolonged depolarizations because of the approaching complete mobilization of the immediately releasable pool (IRP) of vesicles; another reason is the fast inactivation of T-type currents, which limits the quantity of charges for pulse $>100 \mathrm{~ms}$. Exponential time courses for the depolarization-evoked exocytosis are reported also for the HVA channels, with a maximal rate of release of $580 \mathrm{fF} / \mathrm{s}$ [8] and $680 \mathrm{fF} / \mathrm{s}$ [32] for the same cell preparation. As the maximal rate of release is proportional to the channel density, the lower value estimated for T-type channels may just be the consequence of their lower density of expression with respect to HVA channels. A high initial rate of release associated to T-type channels can also be estimated in MPC9/3L cells ( 250 vesicles/s) if assuming that a membrane capacitance change of $1 \mathrm{fF}$ in these cells would correspond to the release of five vesicles with mean diameter between 50 and $100 \mathrm{~nm}$.

A second important observation is that the size of the IRP and the probability of release $(p)$ estimated by doublepulse protocols (Fig. 4a) are comparable to those associated to HVA channels (Fig. 4b). In particular, $p$ is remarkably high ( 0.6 vs. 0.68 for the HVA channels), indicating a high degree of coupling between T-type channels and release sites. It is interesting to notice that the estimate of IRP and $p$ using the double-pulse protocol requires unusually long interpulse intervals $(1.5 \mathrm{~s})$ to recover T-type channels from inactivation so as to have comparable $\mathrm{Ca}^{2+}$ entry during the two pulses. This contrasts with the basic principle of the method, which imposes short interpulse intervals to avoid vesicle refilling during pulses [26]. In the case of T-type channels, however, this causes a $15-20 \%$ overestimate of the IRP that is partially compensated by the $5-10 \%$ decrease of $\mathrm{Ca}^{2+}$ currents during the second pulse.

Finally, the $\mathrm{Ca}^{2+}$ dependence of exocytosis evaluated by plotting the $\Delta C \mathrm{~s}$ vs the corresponding quantity of $\mathrm{Ca}^{2+}$ charges $(\sim 2 \mathrm{pF} / \mathrm{pC})$ is roughly linear and is similar to that estimated for the L-type channels in the same preparation (Fig. 5). This finding has two main implications. First, Ttype and L-type channels couple with the same $\mathrm{Ca}^{2+}$ efficacy to exocytosis. Because the same degree of linearity present between $\mathrm{Ca}^{2+}$ charges and exocytosis exists also for the other $\mathrm{Ca}^{2+}$ channels expressed in RCCs (R, N, and P/ $\mathrm{Q})$, this suggests that in RCCs, there is no preferential coupling between the channels belonging to the $\mathrm{Ca}_{\mathrm{v}} 2$ family and release sites. Second, a high probability of release and a linear $\mathrm{Ca}^{2+}$ dependence similar to that of HVA channels imply that T-type channels contribute to the release of catecholamine at low voltages with the same efficacy that HVA channels contribute to the secretion at high voltages. In addition, considering that T-type channels deactivate at lower rates and that action potentials in RCCs have a prominent and relatively slow repolarization phase, which favor $\mathrm{Ca}^{2+}$ entry through LVA channels, it is likely that the contribution of T-type channels may be determinant during spontaneous action potentials firing near resting (2$3 \mathrm{~Hz}$ ) or during trains of $15-20 \mathrm{~Hz}$. Taken together, all these findings indicate that T-type channels are effectively coupled to exocytosis in RCCs and that they contribute to secretion with the same efficacy of HVA channels normally expressed in RCCs.

\section{T-type channels do not couple to secretion in immature chromaffin cells}

T-type channels do not produce fast secretion coupling at all stages of chromaffin cell development. In embryonic RCCs, LVA channels are expressed in half of the cells but $\mathrm{Ca}^{2+}$ currents through these channels elicited by $160 \mathrm{~ms}$ pulse depolarizations are not able to evoke sizable secretion [7]. On the contrary, secretion measured by capacitance changes and amperometric detection is evident in the other half of cells expressing HVA channels, thus suggesting that vesicles and the overall secretory apparatus is effectively coupled to voltage-gated $\mathrm{Ca}^{2+}$ channels. A possible explanation for the absence of T-type channel secretion coupling is that in immature RCCs, LVA channels are not sufficiently localized to secretory vesicles to induce secretion even when extracellular $\mathrm{Ca}^{2+}$ is raised to produce $\mathrm{Ca}^{2+}$ entry in the order of $60 \mathrm{pC}$. A reason for this could be due to the lower density of T-type channel expression in immature vs mature RCCs $\left(6.5 \mathrm{pA} / \mathrm{pF}\right.$ at $-10 \mathrm{mV}$ in $10 \mathrm{mM} \mathrm{Ba}{ }^{2+}$ vs $15 \mathrm{pA} / \mathrm{pF}$ at $-10 \mathrm{mV}$ in $\left.10 \mathrm{mM} \mathrm{Ca}^{2+},[49]\right)$, but it cannot be excluded the absence of critical factors associated to secretion or an 
increased $\mathrm{Ca}^{2+}$ buffering capacity in immature RCCs that may prevent $\mathrm{Ca}^{2+}$ to reach the release sites when T-type channels are too far apart. This latter condition indeed plays a critical role in chromaffin cells due to the significant distance at which voltage-gated $\mathrm{Ca}^{2+}$ channels are usually located from release sites ( $200 \mathrm{~nm}$ on average) [38]. The lack of secretion does not also seem to depend on the isoform of T-type channels expressed in immature RCCs. In fact, based on the fast inactivation of LVA currents in immature RCCs, it appears that the underlying channel is either the $\alpha_{1 \mathrm{H}}$ or the $\alpha_{1 \mathrm{G}}$ subunit, and both channel types are shown to be effectively coupled to rapid secretion in mature RCCs $\left(\alpha_{1 \mathrm{H}}\right)$ and MPC9/3L cells $\left(\alpha_{1 \mathrm{G}}\right)$.

\section{Are $\alpha_{1 \mathrm{H}}$ T-type channels "stress-induced" channels?}

Overexpression of $\alpha_{1 \mathrm{H}}$ T-type channels during exposure to cAMP [25], $\beta_{1}$-adrenergic stimulation [49], and chronic hypoxia [9, 19], and their effective coupling to catecholamine secretion suggest that T-type channels of chromaffin cells may be conditional in the regulation of adrenal medulla response to stress conditions. Chromaffin cells play a key role in the response to stress and are an excellent model for studying the effects of stress on gene expression. Repeated stress like immobilization periods of $2 \mathrm{~h}$ and hypoxia are shown to produce an immediate release of catecholamines (adrenaline, noradrenaline, and dopamine) in the adrenal medulla. This is followed by a fast upregulation of catecholamine-synthesizing enzymes (TH, $\mathrm{DBH}$, and PNMT) and an increased expression of a number of genes encoding the transcription factors for $\mathrm{TH}, \mathrm{DBH}$, and PNMT mRNA synthesis plus other genes related to kinases/phosphatase signaling and neurosecretion [56].

cAMP plays a key role in the regulation of these processes. The cAMP-response element binding protein is involved in the rapid induction of $\mathrm{TH}$ and $\mathrm{DBH}$ transcription in chromaffin cells [56], and cAMP triggers the rise of the PNMT-promoter-driven gene activity in PC12 cells in hypoxic conditions [62]. Thus, exposure to cAMP, chronic hypoxia, and $\beta_{1}$-adrenergic stimulations (which raise the level of cAMP) appear to be the suitable factors for mimicking prolonged stress conditions in vitro. We found that all these factors induce a common response in RCCs: a marked recruitment of $\alpha_{1 \mathrm{H}}$ T-type channels through cAMPreceptor proteins (Epac) [49]. This lowers the threshold of cell excitability and increases the quantity of catecholamine secreted near resting potentials [25]. Under these conditions, an upregulation of T-type channels effectively coupled to catecholamine release enhances the functional role of these channels during conditions mimicking stressinduced sympathetic stimulations ("fight-or-flight" response). T-type channels appear therefore as key elements of the positive feedback originating from the release of adrenaline and noradrenaline [63], the autocrine activation of $\beta_{1}$-adrenoreceptors [15] and the increased levels of cAMP. These latters activate Epac, transcription factors, gene expression, protein synthesis and trigger important adaptive responses to stressful conditions. An effective availability of T-type channels at potentials near resting $(-50$ to $-60 \mathrm{mV})$ is ensured by the existence of a significant "window" current with peak amplitude at $-45 \mathrm{mV}$ in $10 \mathrm{mM} \mathrm{Ca}^{2+}$ [49] (see also [18]) and by the prolonged repolarization to -60 and $-70 \mathrm{mV}$ between action potentials occurring at 2-3 spikes/s.

\section{Conclusions}

Evidence is accumulating on a key role of T-type channels in transmitter release. Recent works have brought indisputable evidence that T-type channels are capable of controlling hormone and neurotransmitters release in association with the exocytosis of large dense-core and synaptic vesicles. The T-type channel-secretion coupling is not as tight as that reported for $\mathrm{N}$ - and $\mathrm{P} / \mathrm{Q}$-type channels of central neurons, which allows high rates of vesicle release and rapid synaptic responses. Nevertheless, T-type channel-secretion coupling is sufficiently fast to drive the quick fusion of vesicles ready for release during low-threshold $\mathrm{Ca}^{2+}$ fluxes. T-type channels appear to be effectively coupled to rapid vesicle depletion and are possibly involved in the regulation of $\mathrm{Ca}^{2+}$-dependent vesicle recycling, which is an important key process supporting synaptic activity during high-frequency stimulation.

This review aims at furnishing convincing proofs that $\mathrm{T}$ type channels possess all the prerequisites for controlling fast transmitter release in a number of central synapses and secretory cells. It is likely that these observations will soon be extended to other neuronal preparations in which the contribution of LVA channels has been overlooked or not properly investigated. This search would certainly improve if increased attention will be focused on the contribution of Ttype channels to presynaptic $\mathrm{Ca}^{2+}$ currents and if highaffinity selective blockers for LVA channels would become soon available.

Acknowledgements This work was supported by the Italian M.I.U. R. (COFIN grant no. 2005054435), the Piedmont Region (grant no. D14-2005 and D28-2005), and the San Paolo IMI Foundation (grant to the N.I.S. Center of Excellence).

\section{References}

1. Altier C, Zamponi GW (2004) Targeting $\mathrm{Ca}^{2+}$ channels to treat pain: T-type versus N-type. Trends Pharmacol Sci 25:465-470 
2. Armstrong CM, Matteson DR (1985) Two distinct populations of calcium channels in a clonal line of pituitary cells. Science 227: 65-67

3. Bao J, Li JJ, Perl ER (1998) Differences in $\mathrm{Ca}^{2+}$ channels governing generation of miniature and evoked excitatory synaptic currents in spinal laminae I and II. J Neurosci 18:8740-8750

4. Bean BP (1985) Two kinds of calcium channels in canine atrial cells. Differences in kinetics, selectivity, and pharmacology. J Gen Physiol 86:1-30

5. Berntson A, Taylor WR, Morgans CW (2003) Molecular identity, synaptic localization, and physiology of calcium channels in retinal bipolar cells. J Neurosci Res 71:146-151

6. Bossu JL, Feltz A, Thomann JM (1985) Depolarization elicits two distinct calcium currents in vertebrate sensory neurones. Pflugers Arch 403:360-368

7. Bournaud R, Hidalgo J, Yu H, Jaimovich E, Shimar T (2001) Low threshold T-type calcium current in rat chromaffin cells. J Physiol 537:35-44

8. Carabelli V, Giancippoli A, Baldelli P, Carbone E, Artalejo AR (2003) Distinct potentiation of L-type currents and secretion by cAMP in rat chromaffin cells. Biophys J 85:1326-1337

9. Carabelli V, Giancippoli A, Novara M, De Luca A, Carbone E (2005) T-type channel up-regulation by pCPT-cAMP and the hypoxia-mimicking agent deferoxamine in rat chromaffin cells: effects on secretion. Biophys J (Abstract) 88(1):271A-272A Part 2 Suppl

10. Carbone $\mathrm{E}$ (2004) Ion trafficking through T-type $\mathrm{Ca}^{2+}$ channels: a way to look at channel gating position. J Gen Physiol 124: 619-622

11. Carbone E, Lux HD (1984) A low-voltage-activated calcium conductance in embryonic chick sensory neurons. Biophys $\mathrm{J}$ 46:413-418

12. Carbone E, Lux HD (1984) A low-voltage-activated, fully inactivating calcium channel in vertebrate sensory neurons. Nature 310:501-502

13. Carbone E, Lux HD (1987) Single low-voltage-activated calcium channels in chick and rat sensory neurons. J Physiol 386:571-601

14. Catterall WA (2000) Structure and regulation of voltage-gated $\mathrm{Ca}^{2+}$ channels. Annu Rev Cell Dev Biol 16:521-555

15. Cesetti, T, Hernandez-Gujio JM, Baldelli P, Carabelli V, Carbone E (2003) Opposite action of $\beta 1$ - and $\beta 2$-adrenergic receptors on Cav1 L-channel current in rat adrenal chromaffin cells. J Neurosci 23:73-83

16. Clozel JP, Ertel EA, Ertel SI (1999) Voltage-gated T-type $\mathrm{Ca}^{2+}$ channels and heart failure. Proc Assoc Am Phys 11:429-437

17. Cribbs, LL, Lee JH, Yang J, Satin J, Zhang Y, Daud A, Barclay J, Williamson MP, Fox M, Rees M, Perez-Reyes E (1998) Cloning and characterization of alpha1H from human heart, a member of the T-type $\mathrm{Ca}^{2+}$ channel gene family. Circ Res 83:103-109

18. Crunelli V, Toth TI, Cope DW, Blethyn K, Hughes SW (2005) The 'window' T-type calcium current in brain dynamics of different behavioural states. J Physiol 562:121-129

19. Del Toro R, Levitsky KL, Lòpez-Barneo J, Chiara AD (2003) Induction of T-type calcium channel gene expression by chronic hypoxia. J Biol Chem 278:22316-22324

20. Egger V, Svoboda K, Mainen ZF (2003) Mechanism of lateral inhibition in the olfactory bulb: efficiency and modulation of spike-evoked calcium influx into granule cells. J Neurosci 23:7551-7558

21. Egger V, Svoboda K, Mainen ZF (2005) Dendrodendritic synaptic signals in olfactory bulb granule cells: local spine boost and global low-threshold spike. J Neurosci 25:3521-3530

22. Fedulova SA, Kostyuk PG, Veselovsky NS (1985) Two types of calcium channels in the somatic membrane of new-born rat dorsal root ganglion neurones. J Physiol 359:431-446
23. Gandía L, Borges R, Albillos A, García AG (1995) Multiple calcium channel subtypes in isolated rat chromaffin cells. Pflugers Arch 430:55-63

24. Garcia-Palomero E, Cuchillo-Ibanez I, García AG, Renart J, Albillos A, Montiel C (2000) Greater diversity than previously thought of chromaffin cell $\mathrm{Ca}^{2+}$ channels, derived from mRNA identification studies. FEBS Lett 481:235-239

25. Giancippoli A, Novara M, de Luca A, Baldelli P, Marcantoni A, Carbone E, Carabelli V (2006) Low-threshold exocytosis induced by cAMP-recruited $\mathrm{Ca}_{\mathrm{v}} 3.2\left(\alpha_{1 \mathrm{H}}\right)$ channels in rat chromaffin cells. Biophys J 90:1830-1841

26. Gillis KD, Mossner R, Neher E (1996) Protein kinase C enhances exocytosis from chromaffin cells by increasing the size of the readily releasable pool of secretory granules. Neuron 16: $1209-1220$

27. Habermann CJ, O’Brien BJ, Wassel H, Protti DA (2003) All amacrine cells express L-type calcium channels at their output synapses. J Neurosci 23:6904-6913

28. Hamill OP, Marty A, Neher E, Sakmann B, Sigworth FJ (1981) Improved patch-clamp techniques for high-resolution current recording from cells and cell-free membrane patches. Pflugers Arch 391:85-100

29. Harkins AB, Cahill AL, Powers JF, Tischler AS, Fox AP (2003) Expression of recombinant calcium channels support secretion in a mouse pheochromocytoma cell line. J Neurophysiol 90: 2325-2333

30. Hartveit E (1999) Reciprocal synaptic interactions between rod bipolar cells and amacrine Cells in the rat retina. J Neurophysiol 81:2923-2936

31. Hollins B, Ikeda SR (1996) Inward currents underlying action potentials in rat adrenal chromaffin cells. J Neurophysiol 76:1195-1211

32. Horrigan FT, Bookmann RJ (1994) Releasable pools and the kinetics of exocytosis in adrenal chromaffin cells. Neuron 13:1119-1129

33. Huguenard JR (1996) Low-threshold calcium currents in central nervous system neurons. Annu Rev Physiol 58:329-348

34. Ivanov AI, Calabrese RL (2000) Intracellular $\mathrm{Ca}^{2+}$ dynamics during spontaneous and evoked activity of leech heart interneurons: low-threshold $\mathrm{Ca}$ currents and graded synaptic transmission. J Neurosci 20:4930-4943

35. Ivanov AI, Calabrese RL (2003) Modulation of spike-mediated synaptic transmission by presynaptic background $\mathrm{Ca}^{2+}$ in leech heart interneurons. J Neurosci 23:1206-1218

36. Jensen K, Jensen MS, Lambert JD (1999) Role of presynaptic L-type $\mathrm{Ca}^{2+}$ channel in GABAergic synaptic transmission in cultured hippocampal neurons. J Neurophysiol $81: 1225-1230$

37. Jensen K, Mody I (2001) L-type $\mathrm{Ca}^{2+}$ channel-mediated short-term plasticity of GABAergic synapses. Nat Neurosci 4:975-976

38. Klingauf J, Neher E (1997) Modelling buffered $\mathrm{Ca}^{2+}$ diffusion near the membrane: implications for secretion in neuroendocrine cells. Biophys J 72:674-690

39. Lee JH, Gomora JC, Cribbs LL, Perez-Reyes E (1999) Nickel block of three cloned T-type calcium channels: low concentrations selectively block $\alpha 1 \mathrm{H}$. Biophys J 77:3034-3042

40. Leuranguer V, Monteil A, Bourinet E, Dayanithi G, Nargeot J (2000) T-type calcium currents in rat cardiomyocytes during postnatal development: contribution to hormone secretion. Am J Physiol Heart Circ Physiol 279:H2540-H2548

41. Lu J, Dalton IVJF, Stokes DR, Calabrese RL (1997) Functional role of $\mathrm{Ca}^{2+}$ currents in graded and spike-mediated synaptic transmission between leech heart interneurons. J Neurophysiol 77:1779-1794 
42. Mansvelder HD, Kits KS (2000) All classes of calcium channel couple with equal efficiency to exocytosis in rat melanotropes, inducing linear stimulus-secretion coupling. J Physiol 526: 327-339

43. Massie BM (1998) Mibefradil, a T-type channel-selective calcium antagonist: clinical trials in chronic stable angina pectoris. Am J Hypertens 11:95S-102S

44. Mintz IM, Sabatini BL, Regehr WG (1995) Calcium control of transmitter release at a cerebellar synapse. Neuron 15:675-688

45. Mochida S, Westenbroek RE, Yokoyama CT, Zhong H, Myers SJ, Scheurer T, Itoh K, Catterall WA (2003) Requirement for the synaptic protein interaction site for reconstitution of synaptic transmission by P/Q-type calcium channels. Proc Natl Acad Sci U S A 100:2819-2824

46. Murakami N, Ishibashi H, Katsurabayashi S, Akaike N (2002) Calcium channel subtypes on single GABAergic presynaptic terminal projecting to rat hippocampal neurons. Brain Res 951:121-129

47. Neher E, Marty A (1982) Discrete changes of cell membrane capacitance observed under conditions of enhanced secretion in bovine adrenal chromaffin cells. Proc Natl Acad Sci U S A 79:6712-6716

48. Nilius B, Hess P, Lansman JB, Tsien RW (1985) A novel type of cardiac calcium channel in ventricular cells. Nature 316:443-446

49. Novara M, Baldelli P, Cavallari D, Carabelli V, Giancippoli A, Carbone E (2004) Exposure to cAMP and beta-adrenergic stimulation recruits $\mathrm{Ca}_{\mathrm{v}} 3$ T-type channels in rat chromaffin cells through Epac cAMP-receptor proteins. J Physiol 558:433449

50. Nowycky MC, Fox AP, Tsien RW (1985) Three types of neuronal calcium channel with different calcium agonist sensitivity. Nature 316:440-443

51. Pan ZH, Hu HJ, Perring P, Andrade R (2001) T-type $\mathrm{Ca}^{2+}$ channels mediate neurotransmitter release in retinal bipolar cells. Neuron 32:89-98

52. Perez-Reyes E (2003) Molecular physiology of low-voltageactivated T-type calcium channels. Physiol Rev 83:117-161

53. Perez-Reyes E, Cribbs LL, Daud A, Lacerda AE, Barclay J, Williamson MP, Fox M, Rees M, Lee JH (1998) Molecular characterization of a neuronal low-voltage-activated T-type calcium channel. Nature 391:806-900

54. Reid CA, Bekkers JM, Clements JD (2003) Presynaptic $\mathrm{Ca}^{2+}$ channels: a functional patchwork. Trends Neurosci 26:683-687

55. Rossier MF, Lesouhaitier O, Perrier E, Bockhorn L, Chiappe A, Lalevee N (2003) Aldosterone regulation of T-type calcium channels. J Steroid Biochem Mol Biol 85:383-388

56. Sabban EL, Kvetnansky R (2001) Stress-triggered activation of gene expression in catecholaminergic systems: dynamics of transcriptional events. Trends Neurosci 24:91-98

57. Schneggenburger R, Neher E (2000) Intracellular calcium dependence of transmitter release rates at a fast central synapse. Nature 406:889-893
58. Schrier AD, Wang H, Talley EM, Perez-Reyes E, Barrett PQ (2001) Alpha1H T-type $\mathrm{Ca}^{2+}$ channel is the predominant subtype expressed in bovine and rat zona glomerulosa. Am J Physiol Cell Physiol 280:C265-C272

59. Scroggs RS, Fox AP (1992) Multiple $\mathrm{Ca}^{2+}$ currents elicited by action potential waveforms in acutely isolated adult rat dorsal root ganglion neurons. J Neurosci 12:1789-1801

60. Singer JH, Diamond JS (2003) Sustained $\mathrm{Ca}^{2+}$ entry elicits transient postsynaptic currents at a retinal ribbon synapse. J Neurosci 23:10923-10933

61. Spät A, Hunyady L (2004) Control of aldosterone secretion: a model for convergence in cellular signaling pathways. Physiol Rev 84:489-539

62. Tai TC, Wong DL (2003) Protein kinase A and protein kinase C signaling pathway interaction in phenylethanolamine N-methyltransferase gene regulation. J Neurochem 85:816-829

63. Tang, KS, Tse A, Tse FW (2005) Differential regulation of multiple populations of granules in rat adrenal chromaffin cells by culture duration and cyclic AMP. J Neurochem 92:1126-1139

64. Todorovic SM, Jevtovic-Todorovic V, Meyenburg A, Mennerick S, Perez-Reyes E, Romano C, Olney JW, Zorumski CF (2001) Redox modulation of T-type calcium channels in rat peripheral nociceptors. Neuron 31:75-85

65. Triggle DJ (1998) The physiological and pharmacological significance of cardiovascular T-type, voltage-gated calcium channels. Am J Hypertens 11:80S-87S

66. Tsien RW, Clozel JP, Nargeot J (1998) Low voltage-activated Ttype calcium channels. Adis International Limited, Chester, UK

67. Urbano FJ, Piedras-Renteria ES, Jun K, Shin HS, Uchitel OD, Tsien RW (2003) Altered properties of quantal neurotransmitter release at endplates of mice lacking $\mathrm{P} / \mathrm{Q}-$ type $\mathrm{Ca}^{2+}$ channels. Proc Natl Acad Sci U S A 100:3491-3496

68. Vitko I, Chen Y, Arias JM, Shen Y, Wu XR, Perez-Reyes E (2005) Functional characterization and neuronal modeling of the effects of childhood absence epilepsy variants of CACNA1H, a T-type calcium channel. J Neurosci 25:4844-4855

69. Wilkinson MF, Barnes S (1996) The dihydropyridine-sensitive calcium channel subtype in cone photoreceptors. J Gen Physiol 107:621-630

70. Wu LG, Saggau P (1994) Pharmacological identification of two types of presynaptic voltage-dependent calcium channels at CA3CA1 synapses of the hippocampus. J Neurosci 14:5613-5622

71. Wu LG, Westenbroek RE, Borst JG, Catterall WA, Sakmann B (1999) Calcium channel types with distinct presynaptic localization couple differentially to transmitter release in single calyx-type synapses. J Neurosci 19:726-736

72. Yunker AM (2003) Modulation and pharmacology of low voltageactivated ("T-Type") calcium channels. J Bioenerg Biomemb 35:577-598

73. Yunker AM, McEnery MW (2003) Low-voltage-activated ("TType") calcium channels in review. J Bioenerg Biomemb 35: $533-575$ 